\title{
SISTEM KONTROL SUHU AIR MENGGUNAKAN PENGENDALI PID. DAN VOLUME AIR PADA TANGKI PEMANAS AIR BERBASIS ARDUINO UNO
}

\author{
Adiel Megido, Eko Ariyanto \\ Program Studi Diploma III Teknik Elektro \\ Sekolah Vokasi Universitas Diponegoro
}

\begin{abstract}
Adiel Megido, Eko Ariyanto in this paper explain that the temperature control system on water heaters that use electric heaters, generally uses ON-OFF voltage control. Apart from this system being less efficient in using electricity, the limited range of voltage settings provided also lacks the output accuracy value required by the control system. So that for some applications it can cause a response to the temperature control system that oscillates. Another alternative in controlling the heating voltage is by using the PID control method (Proportional - Integral - Derifative), this method provides a wider range of voltage settings, so that it can provide the output accuracy value needed by the control system, thus making it possible to obtain system responses finer (minimum oscillation amplitude).

In addition to problems with the temperature control system, the water volume control system in the water heater tank generally still uses probes that are installed at certain levels. The limitations in reading each change in height / volume of water causes the system output to be less linear (discrete). To produce linear readings and outputs in each change in water volume, a voltage divider can be used.

In this final project design will use an electric water heater tank as a medium to determine the ability of the PID controller to control water temperature according to the set-point and control the height/volume of water in the tank using a voltage divider.
\end{abstract}

Keywords : PID (Proporsional - Integral-Derifatif), Berosilasi, Set-point

\section{PENDAHULUAN \\ Latar Belakang}

Kebanyakan dari sistem kontrol suhu pada Pemanas Air Listrik masih menggunakan pengaturan tegangan secara $O N / O F F$ karena lebih sederhana dan murah. Kelemahan sistem ini adalah boros dalam mengkonsumsi energi listrik, dan suhu air menjadi tidak presisi atau kurang stabil. Alternatif lain dalam mengatur tegangan yang masuk pada pemanas listrik yaitu dengan pengaturan tegangan secara kontrol sudut fasa dengan menggunakan metode kontrol PID (ProportionalIntegral-Derivative) dan PWM (Pulse Width Modulation). Dengan sistem kontrol ini maka dapat mengurangi penggunaan energi listrik, serta menjadikan suhu air lebih presisi dan stabil.

Dalam beberapa modifikasi, Pemanas Air Listrik sudah dilengkapi dengan sistem kontrol volume air, yang otomatis mengisi air ketika wadah mencapai batas habis dan berhenti mengisi air ketika mencapai batas penuh. Namun pada umumnya masih menggunakan probe yang dipasang pada beberapa tingkatan tertentu. Hal ini menyebabkan pembacaan setiap perubahan volume air terbatas, sehingga keluaran sistem menjadi kurang linier (diskrit). Untuk menghasilkan pembacaan dan keluaran yang linier dalam setiap perubahan volume air, dapat memanfaatkan sebuah pembagi tegangan.

Pada penelitian ini dirancang sebuah sistem Tangki Pemanas Air Listrik untuk mengontrol suhu air tetap stabil terhadap setpoint menggunakan pengendali PID dan PWM serta dilengkapi pengukuran dan kontrol volume air.

\section{Batasan Masalah}

Batasan masalah yang dikemukakan penulis pada penelitian ini adalah :

- Sistem kontrol diaplikasikan untuk mengendalikan suhu air dan hanya untuk proses pemanasan secara konstan oleh pemanas listrik 350 Watt.

- $\quad$ Range kontrol suhu adalah $34^{\circ} \mathrm{C}$ sampai dengan $100^{\circ} \mathrm{C} /$ titik didih air dengan kenaikan sebesar $1^{\circ} \mathrm{C}$ sedangkan jangkauan pengukuran suhu adalah $30^{\circ} \mathrm{C}$ sampai dengan $100^{\circ} \mathrm{C} /$ titik didih air.

- Suhu yang dijadikan referensi untuk perhitungan adalah suhu hasil pembacaan dari sensor PT-100 dengan peralatan pengukur suhu standar.

- Pengukuran dan kontrol volume air didalam plant adalah hasil pembacaan dan perhitungan perubahan resistansi potensiometer yang digerakkan oleh sebuah tuas berpelampung.

- Arduino UNO sebagai piranti pemrosesan data untuk mengendalikan suhu dan volume air di dalam plant.

- Tidak memperhitungkan efek perpindahan panas yang terjadi dari sistem ke lingkungan atau sebaliknya.

\section{DASAR TEORI \\ Sistem Kontrol}

Secara umum sistem pengendalian adalah susunan komponen - komponen fisik yang dirakit sedemikian rupa sehingga mampu mengatur sistem nya sendiri atau sistem diluarnya. Sistem kontrol 
adalah proses pengaturan atau pengendalian terhadap satu atau beberapa besaran (variabel, parameter) sehingga berada pada suatu harga range tertentu. Istilah lain sistem kontrol atau teknik kendali adalah teknik pengaturan, sistem pengendalian, atau sistem pengontrolan ( Pakpahan, 1988).

\section{Kontroler On-Off}

Kontroler On-Off hanya bekerja pada dua posisi, yaitu posisi "On" dan posisi "Off" . Kalau contoh objek yang akan dikontrol adalah valve, maka kerja valve hanya terbuka penuh atau tertutup penuh, valve tidak akan pernah bekerja di daerah antara 0$100 \%$. Karena kerjanya yang on-off hasil kontrol onoff akan menyebabkan output/process variable berosilasi penuh dan tidak pernah konstan. (Gunterus, 1994).

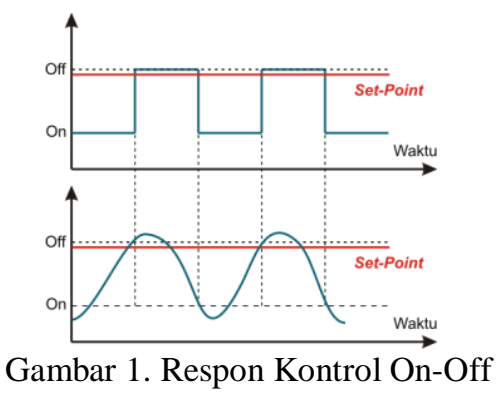

\section{Kontroler PID}

Setiap kekurangan dan kelebihan dari masingmasing pengontrol $\mathrm{P}$, I dan D dapat saling menutupi dengan menggabungkan ketiganya secara paralel menjadi pengontrol proporsional plus integral plus diferensial (pengontrol PID). Elemen-elemen pengontrol $\mathrm{P}$, I dan $\mathrm{D}$ masing-masing secara keseluruhan bertujuan

- Mempercepat reaksi sebuah sistem mencapai set point-nya

- Menghilangkan offset

- Menghasilkan perubahan awal yang besar dan mengurangi overshoot

Dalam perancangan sistem kontrol PID yang perlu dilakukan adalah mengatur parameter P, I, atau D agar tanggapan sinyal keluaran sistem terhadap masukan tertentu sebagaimana yang diinginkan.

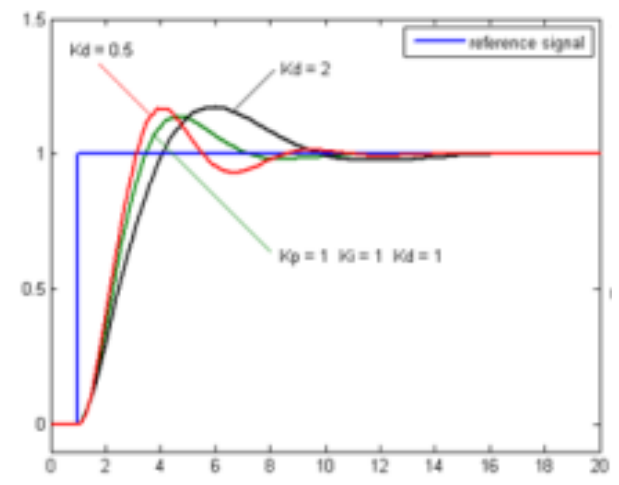

Gambar 2. Respon Kontrol PID

\section{RTD-PT100}

Resistance Temperature Detector (RTD) atau dikenal dengan Detektor Temperatur Tahanan adalah sebuah alat yang digunakan untuk menentukan nilai atau besaran suatu temperatur/suhu dengan menggunakan elemen sensitif dari kawat platina, tembaga, atau nikel murni, yang memberikan nilai tahanan yang terbatas untuk masing-masing temperatur di dalam kisaran suhunya. Semakin panas benda tersebut, semakin besar atau semakin tinggi nilai tahanan listriknya, begitu juga sebaliknya. PT100 merupakan tipe RTD yang paling populer yang digunakan di industri. (Sari B, 2010)

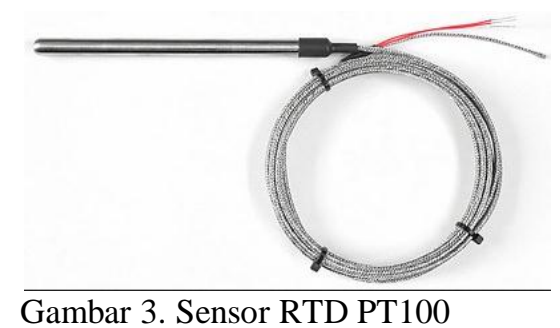

Elemen RTD biasanya ditentukan sesuai dengan resistansi mereka dalam ohm pada nol derajat celcius $\left(0^{0} \mathrm{C}\right)$. Spesifikasi RTD yang paling umum adalah $100 \Omega$ (RTD PT100), yang berarti bahwa pada suhu $0^{0} \mathrm{C}$, elemen RTD harus menunjukkan nilai resistansi $100 \Omega$.

\section{Pengkondisian Sinyal}

PT100 adalah sebuah sensor suhu dimana apabila terjadi perubahan suhu, berubah pula besar resistansinya. Sedangkan input mikrokontroller hanya dapat membaca tegangan dalam level tertentu. Maka dari itu dibutuhkan suatu rangkaian pengkondisi sinyal yang dapat mengubah besar resistansi PT100 ke dalam bentuk tegangan tertentu.

\section{Rangkaian Jembatan Wheatstone}

Rangkaian ini digunakan dalam aplikasi pengkondisi sinyal dimana transduser mengubah tahanan dengan perubahan variabel dinamik. Pada Gambar 2.4 obyek yang diberi label $G$ adalah detektor setimbang yang digunakan untuk membandingkan potensial titik a dan b dari rangkaian.

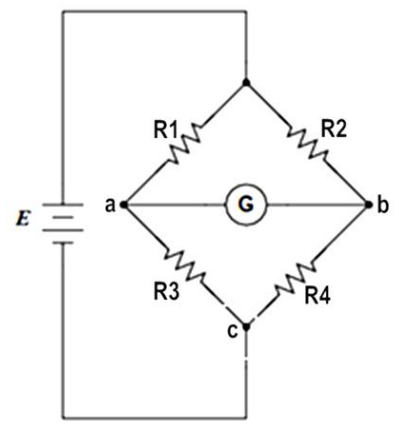

Gambar 4. Jembatan D-C Wheatstone 
Dalam kasus ini beda potensial, $\Delta \mathrm{V}$ antara titik a dan b, adalah

$\Delta \mathrm{V}=\mathrm{Va}-\mathrm{Vb}$

Dimana :

$\mathrm{Va}=$ potensial titik a terhadap $\mathrm{c}$

$\mathrm{Vb}=$ potensial titik $\mathrm{b}$ terhadap $\mathrm{c}$

Setelah beberapa aljabar, memperlihatkan bahwa persamaan ini menjadi :

$\Delta V=V \frac{R_{2} R_{3}-R_{1} R_{4}}{\left(R_{1}+R_{3}\right) .\left(R_{2}+R_{4}\right)} \ldots \ldots$

\section{Penguat OP-AMP Diferensial}

Rangkaian ini memiliki dua input V1 dan V2 pada setiap kutub Op-amp yang berasal dari output rangkaian jembatan wheatstone, Tegangan output (Vout) yang dihasilkan merupakan penjumlahan dari masing-masing Vin $\mathrm{x} \mathrm{K}$. Rumusnya adalah

Vout $=\left(\frac{V 2 \cdot R g}{R 2}\right)-\left(\frac{V 1 \cdot R f}{R 1}\right)$..

Rf dan Rg dapat dibuat sama (Ry), R2 dan R1 dapat dibuat Sama (Rx). Dimana K adalah Ry/Rx. Jadi :

Vout $=\left(\frac{R y}{R x}\right)(V 2-V 1)$ atau

Vout $=K .(V 2-V 1) \ldots(2.4)$

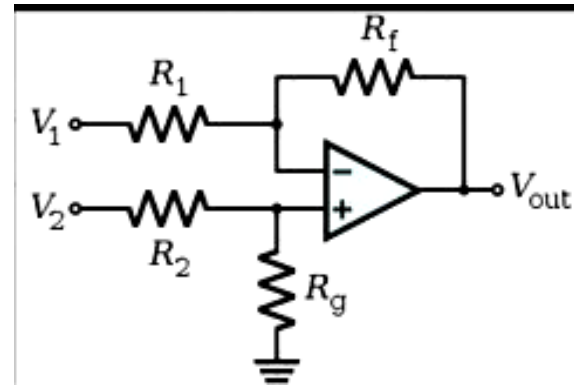

Gambar 5. Rangkaian Penguat Diferensial

\section{Arduino Uno}

Arduino Uno adalah arduino board yang menggunakan mikrokontroler ATmega328. Arduino Uno memiliki 14 pin digital (6 pin dapat digunakan sebagai output PWM), 6 input analog, sebuah 16 $\mathrm{MHz}$ osilator kristal, sebuah koneksi USB, sebuah konektor sumber tegangan, sebuah header ICSP, dan sebuah tombol reset. Arduino Uno memuat segala hal yang dibutuhkan untuk mendukung sebuah mikrokontroler. Hanya dengan menghubungkannya ke sebuah komputer melalui USB atau memberikan tegangan DC dari baterai atau adaptor AC ke DC sudah dapat membuanya bekerja. Tampak atas dari Arduino Uno dapat dilihat pada Gambar 6.

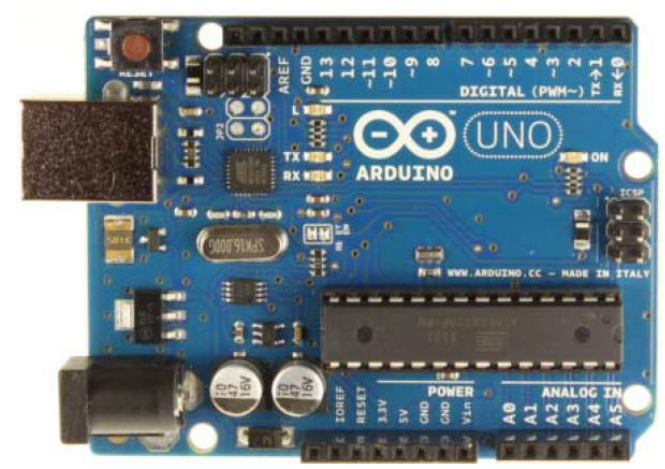

Gambar 6. Arduino Uno

\section{Pulse Width Modulation (PWM)}

PWM adalah singkatan dari Pulse Width Modulation, yaitu teknik yang biasa digunakan untuk mengontrol daya ke perangkat listrik, dibuat praktis dengan switch daya elektronik. PWM digunakan untuk mendapatkan hasil analog dengan cara digital atau lebih singkatnya PWM merupakan cara digital tingkat pengkodean analog.

Salah satu Metode PWM merupakan metoda untuk pengaturan pemanas dengan cara mengatur prosentase lebar pulsa high terhadap perioda dari suatu sinyal persegi dalam bentuk tegangan periodik yang diberikan ke driver heater sebagai pemanas atau dengan kata lain PWM dapat mengatur dengan mudah pemanasan heater sesuai dengan yang diinginkan. Semakin besar perbandingan lama sinyal high dengan perioda sinyal maka semakin besar daya pemanas yang diberikan ke heater.

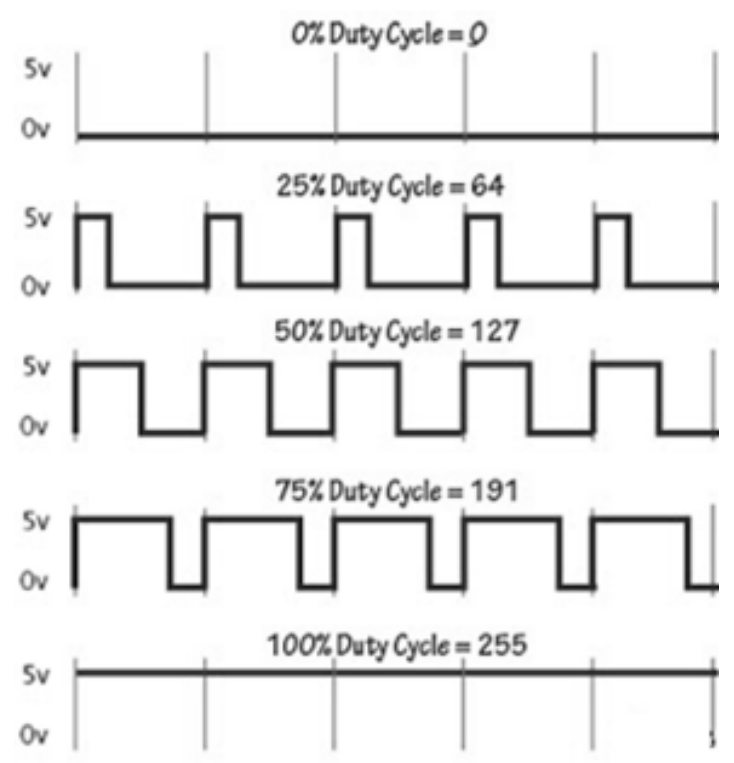

Gambar 7. Duty Cycle PWM Resolusi 8bit 


\section{PERANCANGAN SISTEM DAN CARA KERJA RANGKAIAN \\ Perancangan Perangkat Keras}

Blok diagram dari perangkat keras pada penelitian ini ditunjukkan pada Gambar 8 .

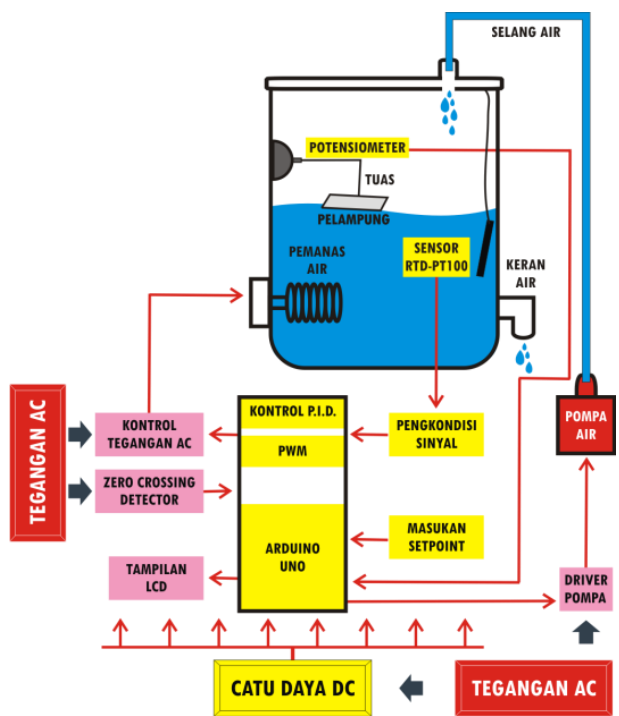

Gambar 8. Blok Diagram Keseluruhan

\section{Rangkaian Catu Daya}

Rangkaian catu daya untuk mensuplai sistem berupa tegangan DC sebesar 5 Volt. Rangkaian catu daya yang baik harus stabil, baik terhadap perubahan jala-jala listrik maupun terhadap perubahan beban.

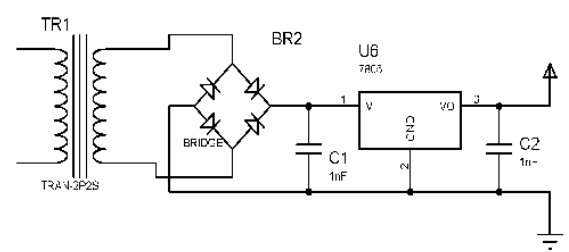

Gambar 9. Rangkaian Catu Daya

Transformator digunakan untuk menurunkan tegangan AC $220 \mathrm{~V}$ menjadi tegangan AC yang lebih rendah. Pada Tugas Akhir ini digunakan satu buah transformator, yaitu transformator 1 A (untuk rangkaian catu daya +5 Volt). Selanjutnya tegangan $\mathrm{AC}$ keluaran transformator masuk ke diode bridge untuk disearahkan menjadi tegangan DC. Tegangan DC yang dihasilkan pada diode bridge masih terdapat riak (ripple), maka dari itu diperlukan kapasitor sebagai filter sehingga akan dihasilkan tegangan DC dengan ripple yang lebih kecil. Setelah itu tegangan masuk ke penstabil tegangan IC regulator 7805. Sehingga tegangan output yang dihasilkan sebesar +5 Volt

\section{Rangkaian Pengkondisi Sinyal}

Pin input pada Arduino Uno hanya dapat membaca nilai tegangan 0-5 VDC sedangkan output yang dihasilkan oleh RTD PT100 berupa nilai hambatan. Oleh karena itu agar output dari RTD
PT100 dapat dibaca oleh Arduino Uno dibutuhkan sebuah pengkondisi sinyal yang terdiri dari rangkaian kesetimbangan jembatan wheatstone dan Penguat Amplifier Diferensial.

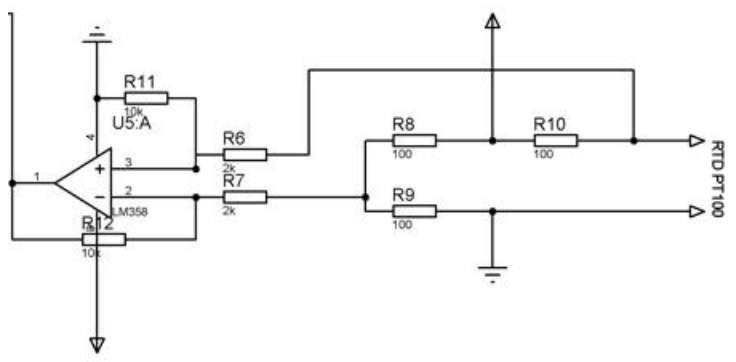

Gambar 10. Rangkaian Pengkondisi Sinyal

Perubahan suhu yang dideteksi oleh RTD PT100 sebanding dengan perubahan nilai hambatannya. Perubahan nilai hambatan ini harus dikonversi menjadi nilai tegangan agar dapat dibaca oleh Arduino UNO, untuk mengubah nilai hambatan menjadi tegangan keluaran Sensor RTD PT100 dihubungkan pada rangkaian jembatan wheatstone. Perbedaan tahanan yang dihasilkan oleh RTD PT100 dengan ketiga tahanan acuan jembatan menghasilkan perbedaan potensial yang nilainya masih kecil dan belum dapat dibaca oleh Arduino UNO. Tegangan yang kecil ini lalu dikuatkan oleh op-amp diferensial menjadi tegangan yang ideal agar dapat dibaca oleh Arduino UNO.

\section{Rangkaian Pembagi Tegangan}

Pembagi Tegangan adalah suatu rangkaian sederhana yang mengubah tegangan besar menjadi tegangan yang lebih kecil. Potensiometer merupakan resistor variable yang sering dipakai sebagai pembagi tegangan. Potensiometer akan berubah nilai Resistansinya dengan cara mengatur atau menggeser bagian poros putar dari Potensiometer tersebut. Potensiometer dapat diasumsikan sebagai dua buah resistor yang di hubungkan secara seri R1 dan R2 tapi dapat dirubah nilai resistansinya. Nilai resistansi total dari resistor akan selalu tetap dan nilai ini merupakan nilai resistansi dari potensiometer. Jika nilai resistansi dari R1 diperbesar dengan cara memutar bagian potensiometer, maka otomatis nilai resistansi dari R2 akan berkurang, begitu juga sebaliknya

Tegangan yang berbeda muncul di setiap resistor menghasilkan sebuah rangkaian yang disebut Rangkaian Pembagi Tegangan yang ditunjukkan oleh Gambar 11. di mana tegangan keluaran adalah tegangan resistor 2 (R2), yang diberikan oleh formula.

$$
\text { Vout }=\frac{R 2}{R 1+R 2} \text { Vin }
$$



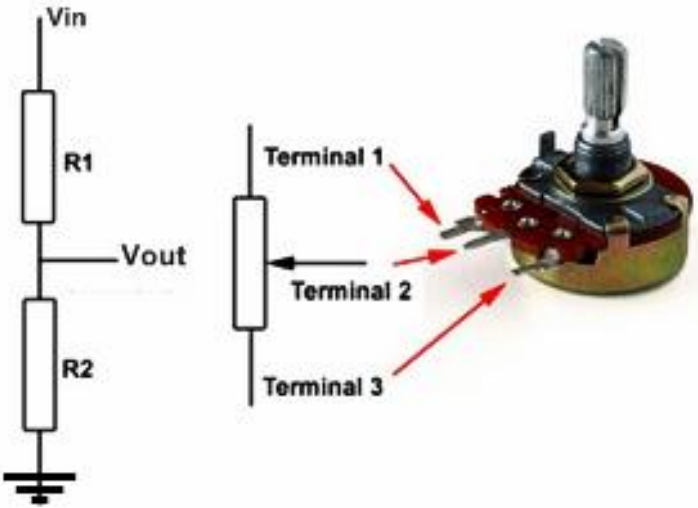

Gambar 11. Rangkaian Pembagi Tegangan

Dalam aplikasi alat, rangkaian ini dimanfaatkan sebagai sensor untuk memonitor dan mengontrol volume air di dalam tangki.. Poros putar pada potensiometer dikaitkan dengan sebuah tuas berpelampung yang berfungsi untuk memutar poros putar pada potensiometer ketika terjadi perubahan volume air.

Variabel tegangan yang dihasilkan karena perubahan resistasi potensiometer, akan diproses oleh Arduino UNO untuk mengetahui volume air di dalam tangki, dan melakukan otomatisasi pengisian tangki ketika volume air mencapai batas minimum dan berhenti mengisi ketika tangki mencapai batas maksimum. Ilustrasi dari proses tersebut ditunjukkan oleh Gambar 12.
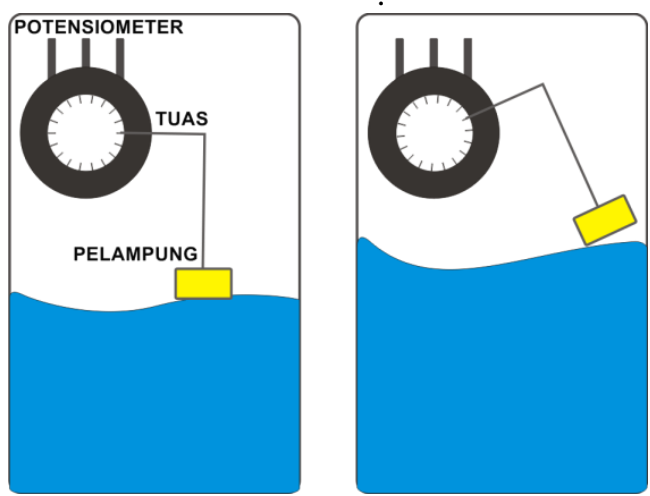

Gambar 12. Sensor Volume Air

\section{Rangkaian Arduino UNO}

Arduino UNO ini menggunakan mikrokontroler ATmega328 yang memiliki 14 pin I/O digital (6 pin diantaranya dapat digunakan sebagai output PWM), 6 analog dan clock yang digunakan $16 \mathrm{MHz}$ (xtal), port usb, jack power supply, dan tombol reset. Arduino UNO memiliki input 14 pin digital yang dapat berfungsi sebagai input dan output. Tegangan input yang dibutuhkan Arduino UNO adalah 5 Volt merupakan otak dari semua proses.

\section{Perancangan Perangkat Lunak}

Perancangan perangkat lunak ini secara garis besar bertujuan untuk mengatur kerja sistem seperti pembacaan hasil sensor, proses pengaturan temperatur sistem dengan menggunakan algoritma kontrol PID digital, menghasilkan sinyal pemicuan triac, memonitor dan mengontrol volume air yang akan menggerakkan aktuator. Dengan demikian perancangan perangkat lunak ini meliputi program utama serta beberapa fungsi-fungsi pendukung. Program utama berperan sebagai jantung perangkat lunak yang akan mengatur keseluruhan operasi yang melibatkan fungsi-fungsi pendukung. Sedangkan fungsi-fungsi pendukung akan melakukan kerja khusus sesuai kebutuhan dari program utama.

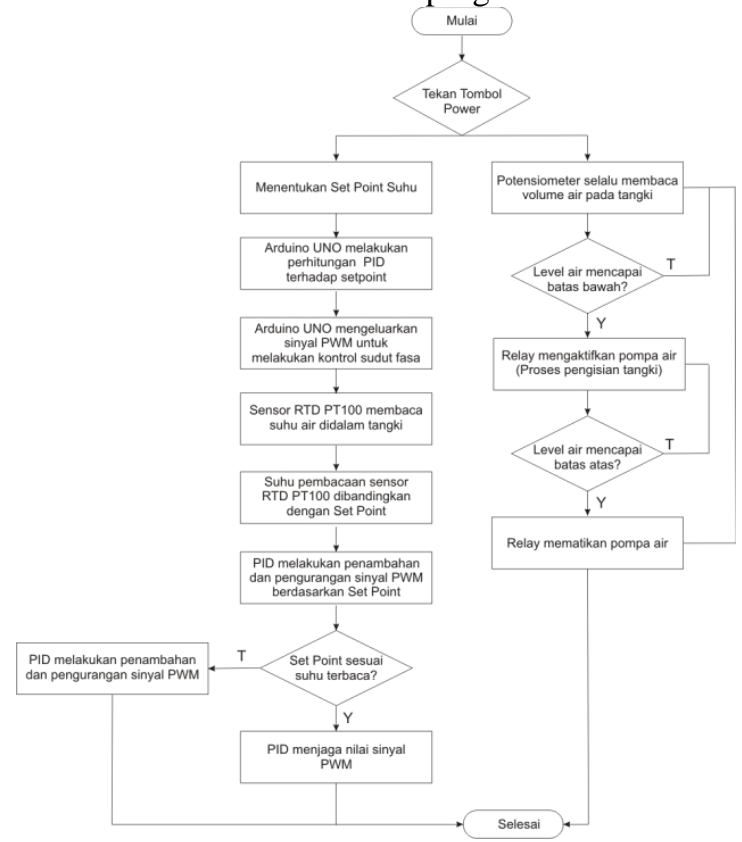

Gambar 13. Diagram Alir Program

\section{Pengendali PID}

Proses pengontrolan dengan menggunakan algoritma kontrol PID digital diimplementasikan dalam program sebagai berikut:

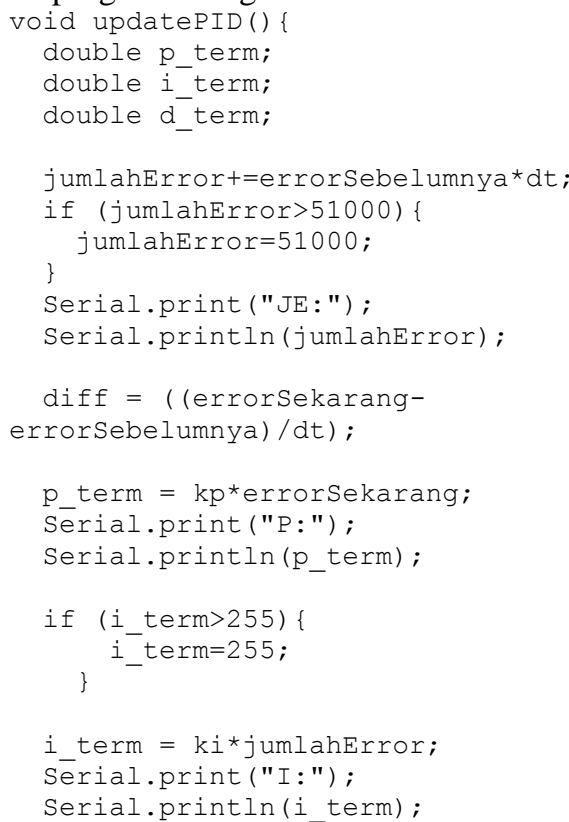




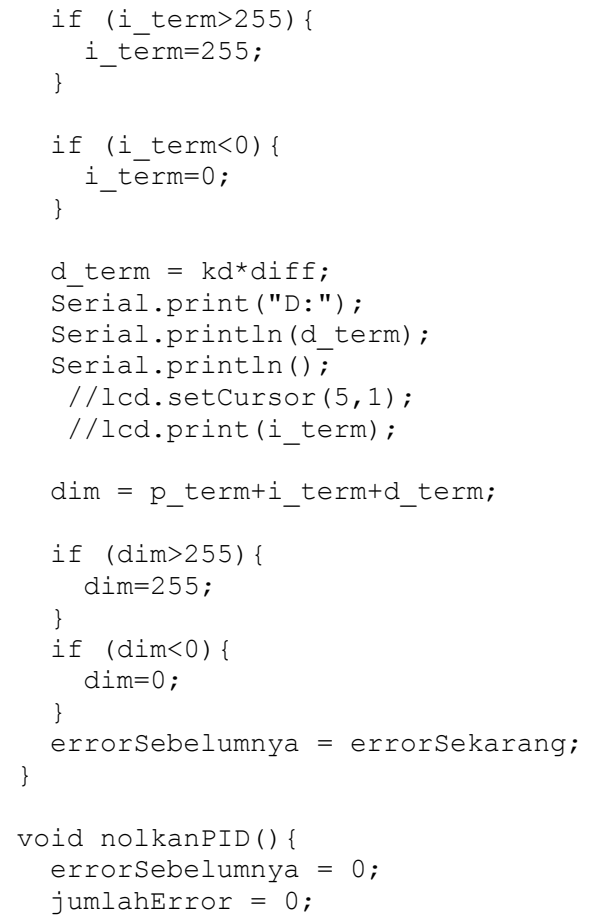

\section{Pengendali Volume Air}

Proses pengontrolan volume air dengan menggunakan rangkaian pembagi tegangan diimplementasikan dalam program sebagai berikut:

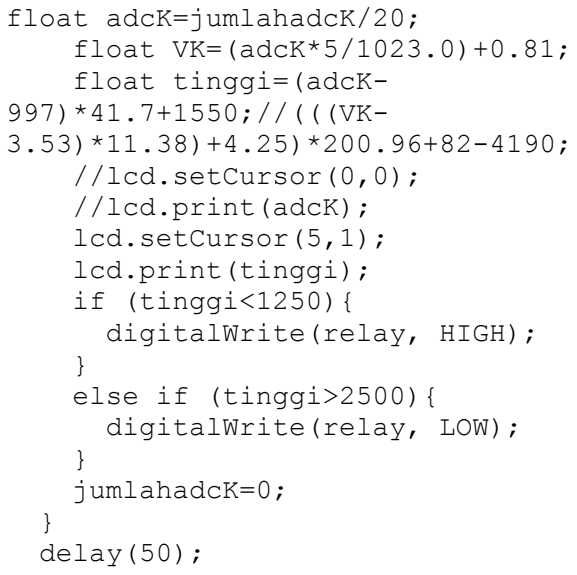

\section{Proses Kerja Alat}

Push button akan terhubung ke ground saat terjadi proses penekanan, dan input akan terbaca low pada proses tersebut, sedangkan ketika tidak ditekan akan terhubung pada 5 Volt. Switch start digunaan untuk memulai pengaturan suhu air dan switch stop untuk menghentikan proses pengaturan suhu air. Sensor RTD-PT100 mendekeksi setiap perubahan suhu dan menghasilkan keluaran berupa perubahan hambatan. Keluaran Sensor RTD PT100 ini kemudian diproses oleh rangkaian pengkondisian sinyal untuk diproses oleh Arduino Uno. Didalam Arduino Uno proses perhitungan Proporsional Integral dan Derivatif (PID) selalu berjalan untuk menghilangkan error yang terjadi antara pembacaan suhu oleh sensor dan setpoint yang diinginkan. Hasil perhitungan PID ini berkaitan erat dengan proses PWM dalam mengatur lebar pulsa yang masuk ke rangkaian kontrol tegangan AC pada heater listrik. Dilain sisi terdapat proses perhitungan volume air dan otomatisasi pengisian tangki oleh potensiometer menggunakan pelampung dan rangkaian driver relay pompa air. Selama plant sistem berjalan, potensiometer selalu mendeteksi perubahan ketinggian air dan dikonversikan ke dalam satuan volume air yang ditampilkan pada LCD. Ketika air di dalam tangki mencapai batas bawah (air di dalam tangki mulai habis), driver relay mengaktifkan pompa air dan mulai mengisi tangki sampai mencapai batas atas (air di dalam tangki mulai penuh) dan otomatis relay mematikan pompa air.

\section{PENGUKURAN DAN PENGUJIAN ALAT Pengukuran Rangkaian}

Pengukuran dan pengujian dilakukan pada masing-masing rangkaian. Hal itu bertujuan untuk mendeteksi kemungkinan adanya kesalahan pada rangkaian. Selain itu juga untuk mengetahui nilai besaran listrik keluarannya.

\section{Rangkaian Pengkondisi Sinyal Sensor Suhu PT100}

Pengukuran pada rangkaian pengkondisi sinyal dilakukan untuk mengetahui hubungan perubahan resistansi sensor PT100 dengan tegangan output pada penguat OPAMP diferensial setelah diproses pada rangkaian jembatan wheatstone. Berikut ini hasil sampling pengukuran tegangan pada titik yang diukur pada rangkaian pengkondisi sinyal

Tabel 1. Pengukuran Rangkaian Pengkondisi Sinyal

\begin{tabular}{cccc}
\hline No & $\begin{array}{c}\text { Suhu } \\
\left({ }^{\circ} \mathrm{C}\right)\end{array}$ & $\begin{array}{c}\text { Output op-amp } \\
(\mathrm{mV})\end{array}$ & $\begin{array}{c}\text { Resistansi } \\
\text { PT100 }(\Omega)\end{array}$ \\
\hline 1 & 35,25 & 1241 & 128,3 \\
2 & 40,10 & 1324 & 130,8 \\
3 & 44,94 & 1397 & 132,2 \\
4 & 49,94 & 1397 & 134,4 \\
5 & 54,95 & 1571 & 135,2 \\
\hline
\end{tabular}

\section{Rangkaian Sensor Volume Air}

Pengukuran pada rangkaian sensor volume air dilakukan untuk mengetahui hubungan perubahan variable tegangan karena resistansi Potensiometer terhadap volume air.

Tabel 2. Pengukuran Rangkaian Sensor Volume Air

\begin{tabular}{cccc}
\hline No. & $\begin{array}{c}\text { Volume } \\
\text { Air }(\mathrm{mL})\end{array}$ & $\begin{array}{c}\text { Tegangan } \\
\text { Output }(\mathrm{V})\end{array}$ & $\begin{array}{c}\text { Resistansi } \\
\text { Potensiometer } \\
(\Omega)\end{array}$ \\
\hline 1 & 1255 & 3,82 & $76,4 \mathrm{k}$ \\
2 & 1501 & 3,92 & $78,4 \mathrm{k}$ \\
3 & 1758 & 4,04 & $80,8 \mathrm{k}$ \\
4 & 2004 & 4,14 & $82,8 \mathrm{k}$ \\
5 & 2250 & 4,25 & $85 \mathrm{k}$ \\
\hline
\end{tabular}




\section{Pengujian Perangkat Keras}

Pengujian perangkat keras dilakukan untuk mengetahui apakah perangkat keras yang telah dirancang dapat bekerja atau berfungsi dengan baik sebagaimana yang diinginkan. Pengujian yang dilakukan terhadap perangkat keras meliputi beberapa blok rangkaian perangkat keras yang telah dirancang dan juga pengujian terhadap gabungan daribeberapa blok rangkaian.

\section{Pengujian Sensor Suhu PT100}

Pengujian sensor suhu dilakukan untuk melihat bagaimana penyimpangan yang dilakukan sensor suhu dalam beberapa kali pengukuran diperlihatkan oleh Tabel 3.

Tabel 3. Pengujian PT100

\begin{tabular}{ccc}
\hline No. & $\begin{array}{c}\text { Suhu Termometer } \\
\left({ }^{\circ} \mathrm{C}\right)\end{array}$ & $\begin{array}{c}\text { Suhu Pembacaan } \\
\left({ }^{\circ} \mathrm{C}\right)\end{array}$ \\
\hline 1 & 30 & 29,92 \\
2 & 35 & 35,25 \\
3 & 40 & 40,10 \\
4 & 45 & 44,94 \\
5 & 50 & 49,94 \\
6 & 55 & 54,95 \\
7 & 60 & 60,2 \\
8 & 65 & 65,12 \\
9 & 70 & 69,92 \\
10 & 75 & 75,13 \\
11 & 80 & 80,28 \\
12 & 85 & 85,45 \\
\hline
\end{tabular}

\section{Pengujian Nilai PWM}

PWM adalah keluaran yang dihasilkan dari perhitungan kontrol PID yang mempengaruhi sudut penyalaan TRIAC untuk mengontrol daya pada heater. Pengujian dilakukan dengan memberikan nilai manual PWM dari duty cycle $0-255(0 \%-$ $100 \%)$. Sampling hasil pengujian untuk tiga kali nilai besar duty cycle PWM ditunjukkan pada Gambar 14 . sampai Gambar 16.

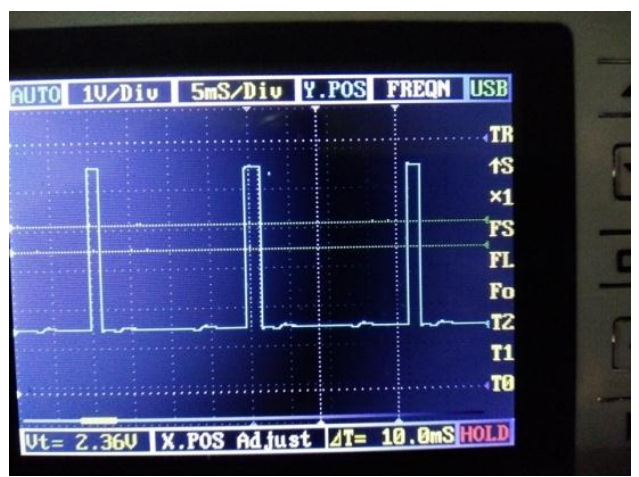

Gambar 14. Duty Cycle PWM 25bit

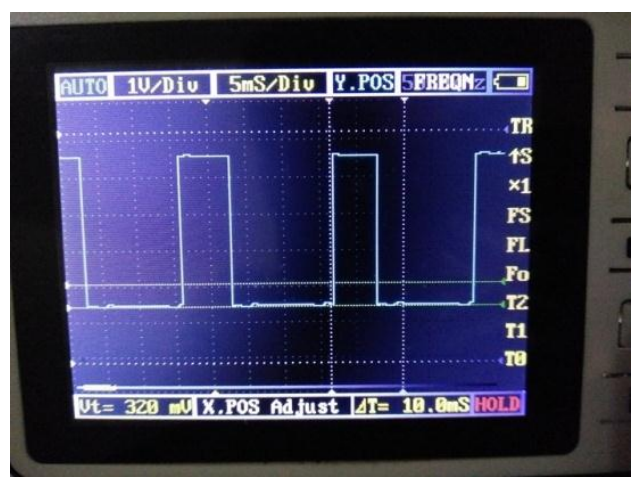

Gambar 15. Duty Cycle PWM 125bit

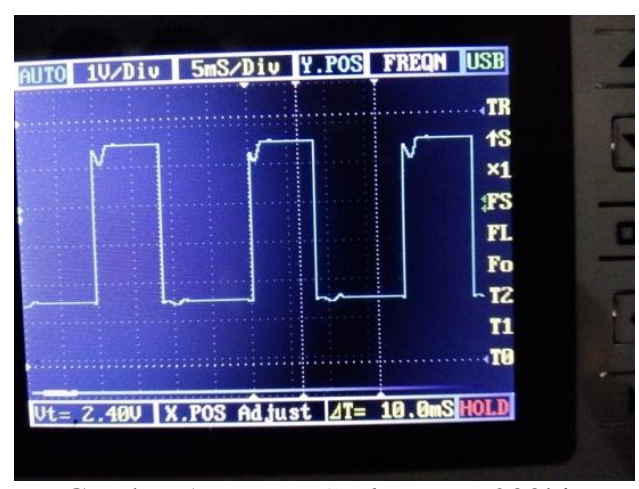

Gambar 16. Duty Cycle PWM 200bit

\section{Pengujian Sistem Keseluruhan}

Pengujian dilakukan untuk mengetahui bagaimana respon sistem pengendalian suhu pada proses pemanasan air bisa bekerja dengan baik sesuai setpoint yang diharapkan. Gambar 4.4 dan gambar 4.5 merupakan hasil respon sistem keseluruhan dengan setpoint $75{ }^{\circ} \mathrm{C}$ dengan parameter $\mathrm{Kp}=65, \mathrm{Ki}=0.0002, \mathrm{Kd}=1$

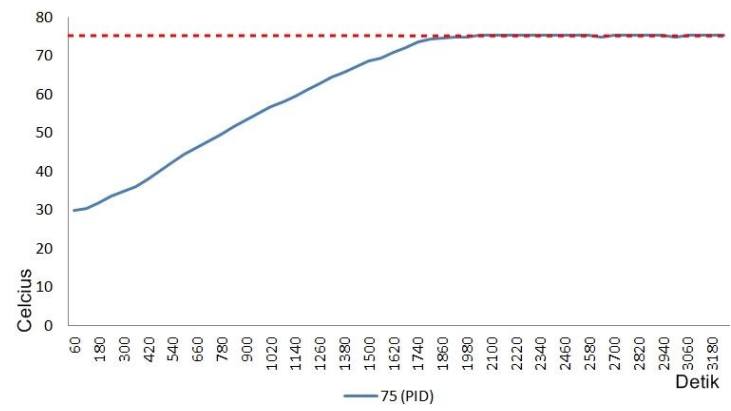

Gambar 17. Respon Kontrol PID set point $75^{\circ}$

Selanjutnya untuk menguji kekokohan sistem dilakukan pengujian dengan memberikan gangguan eksternal. Ketika respon sistem telah mencapai keadaan stabilnya tiba-tiba sistem diberi gangguan dengan menambah air bersuhu lebih rendah. Terlihat pada grafik suhu sempat menurun dan PID dapat memulihkan keadaan sistem sesuai nilai setpoint selama 240 detik 


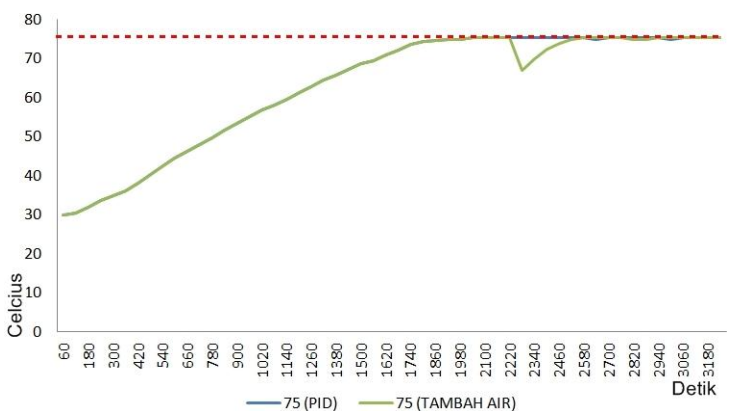

Gambar 18. Respon Kontrol PID set point $75^{\circ}$ Saat diberi Gangguan

\section{KESIMPULAN}

Kesimpulan yang diperoleh dari Tugas Akhir ini sebagai berikut :

- Berdasarkan data respon sistem yang diperoleh dari pengujian dengan metode hand tunning, maka parameter kontroler PID dapat ditentukan dengan gain $\mathrm{Kp}=65, \mathrm{Ki}=0.0002$, dan $\mathrm{Kd}=1$

- Hasil pengujian ini menunjukkan bahwa pengendalian suhu air dengan metode kontrol PID menghasilkan respon sesuai dengan yang diharapkan dan mampu diaplikasikan pada sistem pengendalian suhu karena error yang didapatkan maksimal sebesar $0.3^{\circ} \mathrm{C}$ dan masih dalam toleransi.

- Pembacaan dan pengendalian volume air di dalam tangki menunjukan respon yang baik, namun tegangan input yang terkadang kurang stabil mengakibatkan pembacaan volume air sedikit terganggu.

Beberapa hal yang dapat disarankan sebagai pengembangan dari penelitian ini adalah :

- Implementasi metode pengontrolan lain yang berbasis non-modelling seperti fuzzy, fuzzy hibrid,

- Pembuatan sistem antarmuka antara plant dengan komputer, sehingga respon sistem langsung dapat diamati dalam bentuk grafik dan program untuk mengatur nilai $\mathrm{Kp}, \mathrm{Ki}$, dan $\mathrm{Kd}$ dan Setting Point secara langsung dari komputer.

- Untuk mendapatkan suhu air yang merata dalam tangki dapat ditambahkan mekanisme pengaduk air.

\section{DAFTAR PUSTAKA}

1. Malvino, Albert Paul. 1981. Prinsip-prinsip Elektronik edisi kedua. Jakarta: Erlangga.

2. Gunterus, Frans. 1994. Falsafah Dasar : Sistem Pengendalian Proses.Jakarta:Elex Media Komputindo

3. Efendy, Marwan.n.d. Bab 1 Sistem Pengendalian. Surakarta: Universitas Muhamadiyah Surakarta

4. Bolton, W. 2009. Sistem Instrumentasi dan Sistem Kontrol. Jakarta:Erlangga
5. Ogata, Katsuhiko. 1996. Teknik Kontrol Automatik Jilid 1-2, Diterjemahkan oleh Ir. Edi Laksono. Jakarta : Erlangga.s

6. Petruzella, Frank D. 1996. Elektronika Industri. Yogyakarta: Andi Yogyakarta.

7. Rashid, H Muhammad. 1999. Elektronika Daya Jilid 1. Jakarta: Prehalindo.

8. Michael Tooley, BA. 2003. Rangkaian Elektronik Prinsip dan Aplikasi Edisi kedua. Jakarta : Erlangga.

9. Bishop, Owen. 2004. Dasar-Dasar Elektronika. Jakarta : Erlangga.

10. Majid, Saifulloh Agung. 2009. Pengontrolan Temperatur Menggunakan Metode Kontrol PID Berbasis Mikrokontroler AT90S8515. Semarang: Jurusan Teknik Elektro Fakultas Teknik Universitas Diponegoro.

11. Surono, dkk. 2009. Bahasa Indonesia Untuk Perguruan Tinggi. Semarang: Farindo Press.

12. Laksono, Suryo Krido, Sumardi, dan Aris Triwiyatno. 2010. Pengaturan Sudut Fasa Berbasis Logika Fuzzy Untuk Sistem Pengaturan Temperatur. Semarang: Jurusan Teknik Elektro Fakultas Teknik Universitas Diponegoro.

13. Firsyari, Akhmad Salmi, Purwanto, M Aziz Muslim. 2013. Sistem Pengendalian Suhu Pada Proses Distilasi Vakum Bioetanol Dengan Menggunakan Arduino. Semarang: Jurusan Teknik Elektro Fakultas Teknik Universitas Diponegoro.

14. dan Azaria Mutia Suriatmadja. 2013. Modul Kontrol Temperatur Air Berbasis PID Menggunakan Matlab Simulink. Semarang: PSD III Teknik Elektronika Jurusan Teknik Elektro Politeknik Negeri Semarang. 